\title{
Commentary: Life is unfair, and so are racing sports: some athletes can randomly benefit from alerting effects due to inconsistent starting procedures
}

\author{
Edwin S. Dalmaijer ${ }^{1 *}$, Beorn G. Nijenhuis ${ }^{2}$ and Stefan Van der Stigchel ${ }^{2}$ \\ ${ }^{1}$ Department of Experimental Psychology, University of Oxford, Oxford, UK, ${ }^{2}$ Department of Experimental Psychology, \\ Utrecht University, Utrecht, Netherlands
}

Keywords: alerting, temporal expectancy, foreperiod, racing, sports

\section{A commentary on}

OPEN ACCESS

Edited by:

Kathrin Finke,

Ludwig-Maximilians-Universität

München, Germany

Reviewed by:

Marika Berchicci,

University of Rome "Foro Italico," Italy

Iris Wiegand,

University of Copenhagen, Denmark

${ }^{*}$ Correspondence:

Edwin S. Dalmaijer

edwin.dalmaijer@psy.ox.ac.uk

Specialty section:

This article was submitted to

Cognition,

a section of the journal

Frontiers in Psychology

Received: 30 November 2015

Accepted: 22 January 2016

Published: 09 February 2016

Citation:

Dalmaijer ES, Nijenhuis BG and Van der Stigchel S (2016) Commentary: Life is unfair, and so are racing sports: some athletes can randomly benefit

from alerting effects due to

inconsistent starting procedures.

Front. Psychol. 7:119.

doi: 10.3389/fpsyg.2016.00119
Life is unfair, and so are racing sports: some athletes can randomly benefit from alerting effects due to inconsistent starting procedures

by Dalmaijer, E.S., Nijenhuis, B.G., and Van der Stigchel, S., (2015). Front. Psychol. 6:1618. doi: 10.3389/fpsyg.2015.01618

In some racing sports, regulations require a variable time between the referee's "Ready" cue, and the starting shot. Psychological experiments demonstrate that the length of a pause between such a non-spatial cue and the following signal affects the response to that signal: Reaction times are lowest after an optimal interval of $500 \mathrm{~ms}$, and progressively increase as the interval increases to several seconds (Posner and Boies, 1971; Sanders, 1975). This phenomenon is attributed to a short-lived boost in arousal, and is referred to as the alerting effect. In a recent Perspective article in Frontiers in Psychology, Dalmaijer et al. (2015) argue that alerting effects could allow athletes who start with shorter ready-start intervals (RSIs) to respond quicker to the starting shot. They support their claim with a correlation between RSIs and race times from the 500-m speed-skating event at the 2010 Winter Olympics (Figure 1A), and suggested temporal variability should be removed from starting procedures in racing sports to avoid biased competitions.

News media reported on the study (Daily Mail Online, 2015; Huffington Post, 2015; Süddeutsche Zeitung, 2015). The resulting public attention sparked debates amongst speed-skating enthusiasts and professionals, revolving around two questions: Do quicker athletes somehow produce shorter RSIs, and should the effects of RSIs have been tested earlier into a race? Here, we address the raised concerns with additional data and analyses.

\section{ARE BETTER SKATERS QUICKER TO START?}

Most comments on Dalmaijer et al. argued that correlation does not imply causation to support speculative alternative explanations: Referees could be more nervous with higher-profile athletes, or better athletes could be quicker at assuming their starting positions. Although, no alternative is supported by scientific literature, they would produce the observed correlation between RSI and race time. 


\section{0 meter (finish)}

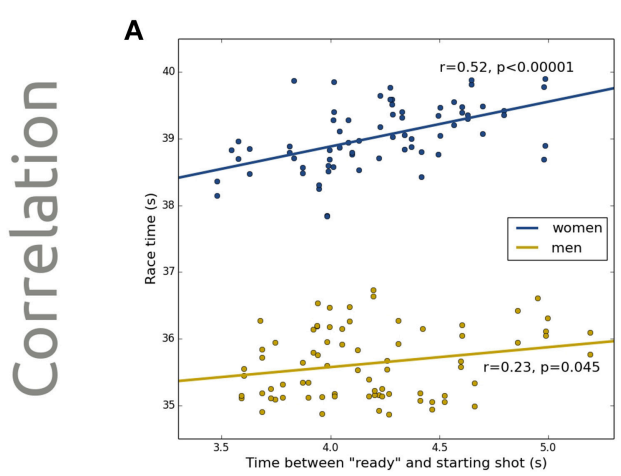

B

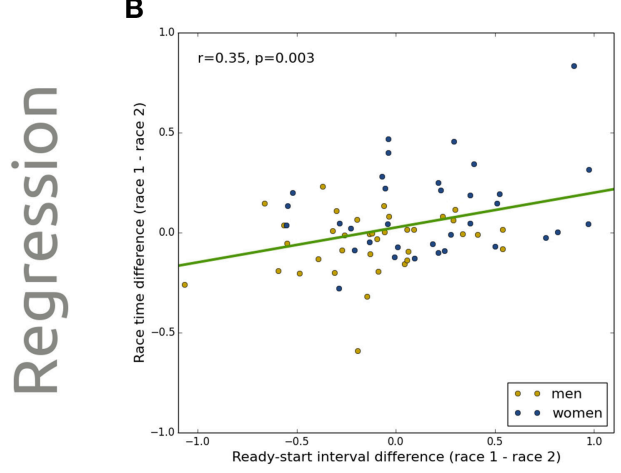

\section{0 meter}

C

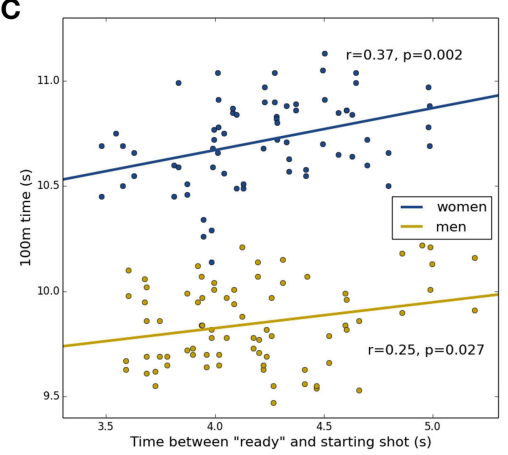

D

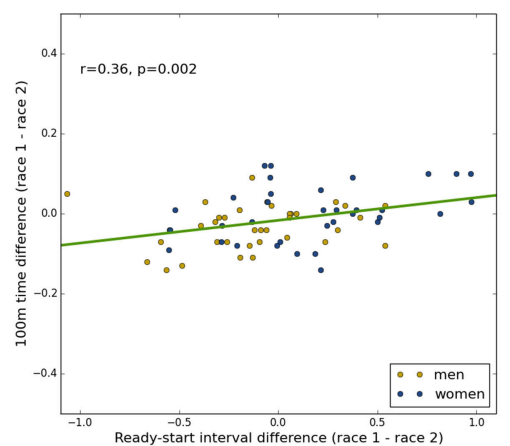

FIGURE 1 | The time between a referee's "Ready" cue and the starting shot is variable, and correlates positively with speed-skaters' times at the finish (A), and $100 \mathrm{~m}$ into their race (C). This is true for men (yellow) and women (blue). Group-level (men and women combined) within-skaters differences in ready-start interval predict within-skaters differences in times at the finish (B) and $100 \mathrm{~m}$ into their race (D).

Borghans (2015) re-analyzed Dalmaijer et al.'s data, capitalizing on how each speed-skater participated in two races. These are independent (each with different RSIs, lane positions, ice conditions, and opponents), making it possible to correlate RSIs of one race with finishing times of the other. There is a significant correlation between one race's RSI and the other race's time for women $(r=0.40, p<0.001)$, but not for men $(r=0.22, p=0.065)$. Borghans argued this demonstrates that better skaters are more consistent, and quicker to start.

Although clever, this approach confounds the effects of skater consistency and RSI. Athletes can be both: consistent in their starts, and affected by RSIs. Thus there should be a correlation between a skater's RSI on one race and their time on the other.

A better approach is to use the difference in RSIs between individual's races to predict the difference in their finishing times. Even if better skaters are quicker to assume position, the relation between these differences should be in the predicted direction. To capture this direction, but not external influences or moderators, one could treat the referee as an experimenter who changes the RSI between two races of the same athlete. In this framework, the RSI difference could be regarded as an independent variable, which would allow causal inferences about its effect on race time differences.
We performed a linear regression on the differences in RSI and race time between the first and the second race of each athlete. One athlete did not participate in both races, and four were excluded for (nearly) falling, leaving 70 samples. RSI difference was a significant $(p=0.003)$ predictor of race time difference, explaining $12 \%$ of the variance (Figure 1B). One additional second of RSI difference led to $174 \mathrm{~ms}$ additional race time difference. Thus, RSIs have an effect on race times, even when accounting for potential confounds.

\section{DO READY-START INTERVALS AFFECT 100-m TIMES?}

Another prevalent question was whether the effect of RSIs on skaters' performance would be present earlier in races. In 500-m speed skating competitions, times are registered $100 \mathrm{~m}$ into the race. A current professional skater expressed that he thought to be highly consistent in his 100-m time, and doubted RSIs would affect this (NOS-Dutch Broadcasting Foundation, 2015a,b). In addition, some noted that if Dalmaijer et al.'s results were due to reduced response times at the start, $100-\mathrm{m}$ times would be a more direct index than finish times. 
An enthusiast kindly supplied us with the 100-m times from the competition analyzed by Dalmaijer et al. We analyzed them exactly as the $500-\mathrm{m}$ times, and found a significant correlation between RSIs and 100-m times for men $(r=0.25, p=0.027$, $N=77)$ and women $(r=0.37, p=0.002, N=70$; Figure 1C). In addition, within-skater differences in RSI were a significant $(p=0.002)$ predictor of within-skater differences in $100-\mathrm{m}$ times, explaining $13 \%$ of the variance (Figure 1D). One additional second of RSI difference led to an additional $59 \mathrm{~ms}$ of 100-m time difference.

\section{FUTURE DIRECTIONS}

Our results indicate that RSIs affect $100-\mathrm{m}$ and finishing times. RSI differences can explain roughly the same variation in 100 and $500-\mathrm{m}$ time differences, and the effect scales from $59 \mathrm{~ms}$ at $100 \mathrm{~m}$ to $174 \mathrm{~ms}$ at $500 \mathrm{~m}$. This is surprising, as Dalmaijer et al.'s (2015) alerting hypothesis concerns athletes' reaction times at the start. During a race, effects of other factors (e.g., athletes' qualities) should account for an increasing proportion of the variance. Therefore, alerting could only be part of the story.

Some suggested that athletes could be sensitive to their own reaction times. Starting slower could lead to reduced motivation or concentration throughout the race, thereby reducing performance.

Others hypothesized that longer RSIs could induce a subtle increase in muscle fatigue. Previous research has shown that muscle fatigue builds up from the onset of exertion, subtly reducing force output within seconds (Bigland-Ritchie et al.,

\section{REFERENCES}

Bigland-Ritchie, B., Johansson, R., Lippold, O. C., and Woods, J. J. (1983). Contractile speed and EMG changes during fatigue of sustained maximal voluntary contractions. J. Neurophysiol. 50, 313-324.

Borghans, L. (2015). Schaatsers Moeten Niet te Snel Zijn [Skaters Shouldn't be Too Quick]. Available online at: http://www.economie.nl/weblog/schaatsersmoeten-niet-te-snel-zijn

Dalmaijer, E. S., Nijenhuis, B. G., and Van der Stigchel, S. (2015). Life is unfair, and so are racing sports: some athletes can randomly benefit from alerting effects due to inconsistent starting procedures. Front. Psychol. 6:1618. doi: 10.3389/fpsyg.2015.01618

Daily Mail Online (2015). Race Starts Could Give Some Athletes an "Unfair Advantage": Long Gap Between "Ready" and "Bang" of the Starting Pistol Can Cost Competitors a Medal. Available online at: http://www.dailymail.co.uk/ sciencetech/article-3293529/Race-starts-athletes-unfair-advantage-Longgap-ready-bang-starting-pistol-cost-competitors-medal.html

Huffington Post (2015). Here's How Some Race Starts May Give Athletes an Unfair Advantage. Available online at: http://www.huffingtonpost.com/entry/start-of-race-influences-an-athletes-perf ormance_56326adae4b00aa54a4d55c0

Kent-Braun, J. A. (1999). Central and peripheral contributions to muscle fatigue in humans during sustained maximal effort. Eur. J. Appl. Physiol. Occup. Physiol. 80, 57-63. doi: 10.1007/s0042100 50558
1983; Kent-Braun, 1999). However, it is unclear whether this could have an effect on athletes' performance.

\section{CONCLUSION}

Although Dalmaijer et al.'s (2015) analysis could have been more elegant, the theoretical framework was valid, and the claims hold up in more stringent analyses. We demonstrate that differences in ready-start intervals predict differences in finishing times. Although the underlying mechanisms should be investigated in future experimental research, sports unions would be wise to exercise caution with the current starting procedures.

\section{AUTHOR CONTRIBUTIONS}

All authors conceived the idea. ED collected and analyzed the data. ED drafted the manuscript, and $\mathrm{BN}$ and SV provided critical comments.

\section{ACKNOWLEDGMENTS}

We would like to thank all sports enthusiasts and professionals that provided comments on Dalmaijer et al. (2015), in particular Prof. Lex Borghans for his re-analysis of our data, and Dr. Fokko van de Bult for providing the 100-m times analyzed here. ED was supported through European Union FP7 Marie Curie ITN Grant No. 606901 (INDIREA). SV was supported by a VIDI grant 452-13-008 from the Netherlands Organisation for Scientific Research.

NOS-Dutch Broadcasting Foundation (2015a). Mulder "Gelooft Niet Zo" In Nieuwe Startprocedure [Mulder "Doesn't Quite Believe" in New Starting Procedure]. Available online at: http://nos.nl/artikel/2065428-mulder-gelooft-niet-zo-innieuwe-startprocedure.html

NOS-Dutch Broadcasting Foundation (2015b). "Nieuwe Startprocedure? Daar Kan Ik Niets Mee" ["New starting procedure? Doesn't Work for Me"]. Available online at: http://nos.nl/video/2065418-nieuwe-startprocedure-daarkan-ik-niets-mee.html

Posner, M. I., and Boies, S. J. (1971). Components of attention. Psychol. Rev. 78, 391-408. doi: 10.1037/h0031333

Sanders, A. F. (1975). The foreperiod effect revisited. Q. J. Exp. Psychol. 27, 591-598. doi: 10.1080/14640747508400522

Süddeutsche Zeitung (2015). Achtung, Fertig! Pause [Ready-start interval]. Available online at: http://www.sueddeutsche.de/wissen/sportpsychologieachtung-fertig-pause- 1.2712164

Conflict of Interest Statement: The authors declare that the research was conducted in the absence of any commercial or financial relationships that could be construed as a potential conflict of interest.

Copyright (c) 2016 Dalmaijer, Nijenhuis and Van der Stigchel. This is an open-access article distributed under the terms of the Creative Commons Attribution License (CC $B Y)$. The use, distribution or reproduction in other forums is permitted, provided the original author(s) or licensor are credited and that the original publication in this journal is cited, in accordance with accepted academic practice. No use, distribution or reproduction is permitted which does not comply with these terms. 